\title{
Antioxidant, Hepatoprotective, and Anthelmintic Activities of Methanol Extract of Urtica dioica L. Leaves
}

\author{
Manjir Sarma Kataki*, ${ }^{*}, 2$, Veerukannayan Murugamani ${ }^{1}$, Ananya Rajkumari ${ }^{1}$, Prahlad Singh \\ Mehra $^{1}$, Deepak Awasthi ${ }^{2}$, Ravi Shankar Yadav ${ }^{2}$ \\ ${ }^{1}$ Abhilashi College of Pharmacy, Tanda, Ner-chowk, Mandi, Himachal Pradesh-175008, India; ${ }^{2}$ Ancient Herbal Waves, \\ Haridwar, Uttarakhand-249407, India
}

\begin{abstract}
The antioxidant, hepatoprotective, and anthelmintic activities of methanol extract of leaves of Urtica dioica L. (MEUD) were investigated in the present study. Hepatoprotective potential of the extract was evaluated against $\mathrm{CCl}_{4}-$ induced hepatic injury in Wister rats. In addition, reducing power assay, determination of total antioxidant activity, DPPH radical scavenging activity and nitric oxide scavenging activity were investigated to evaluate the in vitro antioxidant activity of the extract. The results indicated significant antioxidant activity of the extract comparable to standard antioxidant compounds like $\alpha$-tocopherol, ascorbic acid and BHA (Butylated hydroxyanisole). Significant hepatoprotective profile was also observed with maximum hepatoprotection at the dose of $400 \mathrm{mg} / \mathrm{kg}$ as suggested by decreased level of serum ALT, AST, ALP and total bilirubin levels towards normalization. Pretreatment of animals with the extract at all the dose level $(100,200$, and $400 \mathrm{mg} / \mathrm{kg}$ ) resulted a significant decrease in malonyldehyde (MDA) level as well as a significant increase in superoxide dismutase (SOD) level clearly indicating inhibition of lipid peroxidation and improvement of antioxidant defense enzyme system. Anthelmintic activity of the methanol extract was also investigated using adult Indian earth worms (Pheretima posthuma) and the results revealed a dose dependent increase in anthelmintic activity of the extract at 25,50 , and $100 \mathrm{mg} / \mathrm{mL}$ concentrations.
\end{abstract}

Keywords: Urtica dioica, Reducing power, Antioxidant, Anthelmintic, DPPH radical, Nitric oxide, Carbon tetrachloride, Hepatoprotective.

\section{INTRODUCTION}

Urtica dioica L. (Urticaceae) is a traditional Ayurvedic herb and also known as Vrishchhiyaa-shaaka. It is also known as Bichu Butti in Hindi and Punjabi, Anjuraa in Unani, Shisuun in folk language (Kumaon) and Stinging Nettle in English [1,2]. The plant is an annual and perennial herb available in many South Asian Countries and in the Indian subcontinent and has been known in the world as a medicinal herb for a long time. It is also found in Assam, Arunachal Pradesh and Himachal Pradesh [1,2]. The plant is used traditionally as diuretic, emmenagogue, blood purifier and as anthelminthic $[1,2]$. It is also used in nephritis, haematuria, jaundice and menorrhagia [1]. Moreover, previous studies reported the presence of lectins, linolenic acid, lutein, lutein isomers, b-carotene and b-carotene isomers, neoxanthin, violaxanthin and lycopene in this plant. The herb is also claimed to possess diuretic and natriuretic effects along with antidiabetic and antihypertensive activity [3-10].

Antioxidants from natural original are extensively on use over the past years. Most diseases like cardiovascular diseases, inflammation, cancer, osteoporosis, degenerative diseases etc. are coupled with Reactive Oxygen Species (ROS)

*Address correspondence to this author at the Abhilashi College of Pharmacy, Tanda, Ner-chowk, Mandi, Himachal Pradesh-175008, India; Tel: +91 9816193805; E-mail: manjirkataki@gmail.com production, Reactive Nitrogen Species production and oxidative stress theory [11]. The free radicals mainly act by attacking the unsaturated fatty acid in the biological membranes which extend to membrane lipid peroxidation, decrease in membrane fluidity, and reduction of antioxidant defense enzymes, receptor activity and damage to membrane protein. These destructive processes finally triggers the cell inactivation or death $[12,13]$. Antioxidants therefore can be used to reverse the harmful and pathological effect of the free radicals. The antioxidants generally scavenge the free radicals and detoxify the physiological system. The free radicals are normally generated during normal body metabolic function and also can be acquired from the environment. Free radicals can be oxygen radicals, such as superoxide radical $\left(\mathrm{O}_{2}{ }^{-}\right)$, hydroxyl radical $\left({ }^{\circ} \mathrm{OH}\right)$ and non free radical species, such as hydrogen peroxide $\left(\mathrm{H}_{2} \mathrm{O}_{2}\right)$ and singlet oxygen $\left({ }^{\circ} \mathrm{O}_{2}\right)$, and are generated in many redox processes [14]. Superoxide dismutase, catalase and glutathione peroxidase etc are the enzymes of antioxidant defense system which trap and destroy these free radicals [13]. Vitamin deficiency along with excess production of free radicals, a decreased level of antioxidant defense enzymes and increased lipid peroxidation are considered as the perpetrators for producing oxidative stress and linked with various pathological conditions [15].

Local communities and folklore healers throughout the world use a wide range of plants and their parts for their medicinal properties. A large population from folk and tribal 
communities still uses a variety of plants for medicinal purposes due to either lack of advanced health care facilities in their remote regions or their traditional belief along with the success rate of these traditional medicines in different disease conditions. Moreover, a large number of bioactive drugs currently in use in modern system of medicine came from medicinal plants only. Medicinal plants are now considered as potential source for new bioactive leads or drugs.

The present study was designed to examine the antioxidant and hepatoprotective activities of methanol extract of leaves of $U$. dioica. Preliminary phytochemical screening of the methanol extract was also done along with the determination of total phenolic content. It was also of interest to find out the anthelmintic activity of the extract against adult Indian earth worms for a clear justification of the ayurvedic and traditional folklore use of this plant in worm infestation.

\section{MATERIALS AND METHODS}

\section{Plant Materials}

Leaves of $U$. dioica were collected from Balh Valley of Mandi district of Himachal Pradesh (India) and authenticated by Dr. S. K. Sharma, Botanist, Research Institute in Indian System of Medicine, Joginder Nagar, Mandi, Himachal Pradesh. A voucher specimen herbarium (MSK/ACP/D1/10/2010) was deposited in the Pharmacognosy department, Abhilashi College of Pharmacy, Mandi, Himachal Pradesh for future reference.

\section{Drugs and Chemicals}

Chemicals, such as Folin-Ciocalteau reagent, trichloroacetic acid (TCA), methanol, ammonium thiocyanate, dimethylsulphoxide (DMSO), gallic acid, $\alpha$ Tocopherol, butylated hydroxyanisole (BHA), carbon tetrachloride $\left(\mathrm{CCl}_{4}\right)$ were purchased from E. Merck (India) Limited. Linoleic acids, Sulphanilamide, N-(1-naphthyl) ethylenediamine dihydrochloride, ascorbic acid, DPPH, and malondialdehyde (MDA) were procured from Sigma Chemicals Company, St Louis, MO, USA. Petroleum ether, Tween 80 and all other chemicals and solvents used were of analytical grade available commercially (SRL Mumbai, Himedia, E.Merck India). Silymarin, streptomycin, albendazole and piperazine citrate were arranged by Aura Pharmaceuticals, Mandi, Himachal Pradesh as gift samples.

\section{Preparation of Extracts}

The leaves of $U$. dioica were shade dried and then powdered. The powdered plant leaves were extracted with methanol as solvent using Soxhlet apparatus and then concentrated in-vacuo. Approximately, $3.5 \mathrm{gm}$ of dried methanol extract of $U$. dioica leaves (MEUD) was obtained from $50 \mathrm{~g}$ of dried leaf material (Yield, 7\%).

\section{Preliminary Phytochemical Screening}

Preliminary phytochemical screening for identification of the chemical constituents were carried out on the powdered drug as well as on the methanol extract using chemical methods according to the methodology proposed elsewhere [16].

\section{Determination of Total Phenolic Content}

Total soluble phenolic content in MEUD was determined by using Folin-Ciocalteau method using gallic acid as a standard phenolic compound [17]. About $1.0 \mathrm{~mL}$ of extract (10 mg of extract) was diluted with $46 \mathrm{~mL}$ of distilled water in a volumetric flask. Folin-Ciocalteau reagent $(1 \mathrm{~mL})$ was added to the above mixture and mixed thoroughly. Three minutes later $3.0 \mathrm{~mL}$ of $2 \%$ sodium carbonate was added and the mixture was allowed to stand with intermittent shaking for $3 \mathrm{~h}$. The absorbance of the mixture was measured at 760 $\mathrm{nm}$ in a spectrophotometer (UV -1601 Shimadzu, Japan). The concentration of total phenols was expressed as $\mathrm{mg} / \mathrm{g}$ of extract. The concentration of total phenolic compounds in the extract was expressed as gram of gallic acid equivalent (GAE) using an equation obtained from the equation of regression line of standard gallic acid graph:

$\mathrm{Y}=0.002 \mathrm{x}+0.070, \mathrm{r}^{2}=0.9550$

Where, $\mathrm{y}$ was the absorbance and $\mathrm{x}$ was the concentration.

\section{In Vitro Antioxidant Activity}

\section{Total Antioxidant Activity}

The thiocyanate method was used for determination of the total antioxidant activity of MEUD [18]. Accordingly ten milligrams of extract was dissolved in $10 \mathrm{~mL}$ water. Different concentration of extract $(50-250 \mu \mathrm{g} / \mathrm{mL})$ or standard samples in $2.5 \mathrm{~mL}$ of potassium phosphate buffer $(0.04 \mathrm{M}$, $\mathrm{pH} 7.0)$ was added to linoleic acid emulsion $(2.5 \mathrm{~mL})$ in potassium phosphate buffer $(0.04 \mathrm{M}, \mathrm{pH} 7.0)$. Five milliliters linoleic acid emulsion comprises of $17.5 \mathrm{mg} / \mathrm{g}$ of Tween-20 (as emulsifier), $15.5 \mu \mathrm{L}$ linoleic acid, and $0.04 \mathrm{M}$ potassium phosphate buffer ( $\mathrm{pH} 7.0$ ). On the contrary, $5.0 \mathrm{~mL}$ control consists of $2.5 \mathrm{~mL}$ linoleic acid emulsion and $2.5 \mathrm{~mL}$ potassium phosphate buffer $(0.04 \mathrm{M}, \mathrm{pH} 7.0)$. The mixture was incubated at $37^{\circ} \mathrm{C}$ in the dark. After the mixture was stirred for $3 \mathrm{~min}$, the peroxide value was determined by measuring the absorbance at $500 \mathrm{~nm}$ in a spectrophotometer (UV -1601 Shimadzu, Japan), after reaction with $\mathrm{FeCl}_{2}$ and thiocyanate at intervals during incubation. During the linoleic acid oxidation, peroxides formed. These compounds oxidize $\mathrm{Fe}^{2+}$ to $\mathrm{Fe}^{3+}$. The latter $\mathrm{Fe}^{3+}$ ions form complex with $\mathrm{SCN}^{-}$, which had maximum absorbance at $500 \mathrm{~nm}$. Therefore, high absorbance indicates high linoleic acid oxidation. The solutions without extract or standards were used as blank samples. All data about total antioxidant activity are the average of triplicate analyses. The inhibition of lipid peroxidation in percentage was calculated by following equation:

Inhibition $(\%)=\left(A_{0}-A_{t} / A_{0}\right) \times 100$

Where $A_{0}$ was the absorbance of the control reaction and $A_{t}$ was the absorbance in the presence of the sample. All the tests were performed in triplicate and graph was plotted with the mean \pm SD values. As standard antioxidant compound, $\alpha$-Tocopherol was used.

\section{Reducing Power}

The reducing power of MEUD was determined according to the method described previously $[13,19]$. The different concentrations of extract $(50-250 \mu \mathrm{g} / \mathrm{mL})$ in $1 \mathrm{~mL}$ of distilled water was mixed with phosphate buffer $(2.5 \mathrm{~mL}, 0.2$ 
$\mathrm{M}, \mathrm{pH}$ 6.6) and potassium ferricyanide $\left[\mathrm{K}_{3} \mathrm{Fe}(\mathrm{CN})_{6}\right](2.5$ $\mathrm{mL}, 1 \%$ ). The mixture was incubated at $50{ }^{\circ} \mathrm{C}$ for $20 \mathrm{~min}$. A portion $(2.5 \mathrm{~mL})$ of trichloroacetic acid $(10 \%)$ was added to the mixture, which was then centrifuged for $10 \mathrm{~min}$ at 3000 $\mathrm{rpm}$. The upper layer of solution $(2.5 \mathrm{~mL})$ was mixed with distilled water $(2.5 \mathrm{~mL})$ and $\mathrm{FeCl}_{3}(0.5 \mathrm{~mL}, 0.1 \%)$, and the absorbance was measured at $700 \mathrm{~nm}$ in a spectrophotometer (UV -1601 Shimadzu, Japan). Higher absorbance of the reaction mixture indicated greater reducing power. $\alpha$-Tocopherol was used as standard antioxidant compound.

\section{Determination of DPPH (1-1-Diphenyl- 2-Picryl Hydrazyl) Radical Scavenging Activity}

The free radical scavenging activity of MEU) was measured by DPPH $\bullet$ radical using the method described previously with a little modification [20]. A $0.1 \mathrm{mM}$ solution of $\mathrm{DPPH} \cdot$ in ethanol was prepared and $1 \mathrm{~mL}$ of this solution was added to $3 \mathrm{~mL}$ of extract solution in water at different concentrations $(50-250 \mu \mathrm{g} / \mathrm{mL})$. The mixture was shaken energetically and allowed to stand at room temperature for $40 \mathrm{~min}$. Then the absorbance was measured at $517 \mathrm{~nm}$ in a spectrophotometer (UV -1601 Shimadzu, Japan). Lower absorbance of the reaction mixture indicated higher free radical scavenging activity. The percent DPPH scavenging effect was calculated using the following equation: 100].

$\mathrm{DPPH}^{*}$ scavenging effect $(\%)=100-\left[\left(\mathrm{A}_{0}-\mathrm{A}_{\mathrm{t}} / \mathrm{A}_{0}\right) \times\right.$

Where $\mathrm{A}_{0}$ was the absorbance of the control reaction and $A_{t}$ was the absorbance in the presence of the standard sample or extract. All the tests were performed in triplicate and graph was plotted with the mean \pm SD values. BHA (Butylated hydroxyanisole) was used as standard antioxidant compound.

\section{Assay of Nitric Oxide Scavenging Activity}

A method based on Greiss reaction was used for evaluation of nitric oxide scavenging activity [21, 22]. In aqueous solution, sodium nitroprusside generates nitric oxide ad libitum at physiological $\mathrm{pH}$, which interacts with oxygen to produce nitrite ions that can be estimated using Greiss reagent. Scavengers of nitric oxide compete with oxygen leading to reduced production of nitrite ions. Sodium nitroprusside (10 $\mathrm{mM}$ ) in phosphate buffered saline was mixed with different concentrations of MEUD dissolved in methanol and then incubated at room temperature for 150 minutes. In the same way, a reaction mixture was prepared without the methanol extract but with equivalent amount of methanol was added. This served as control. After the incubation period, $0.5 \mathrm{~mL}$ of Greiss reagent ( $1 \%$ Sulphanilamide, $2 \% \mathrm{H}_{3} \mathrm{PO}_{4}$ and 0.1 $\% \mathrm{~N}$-(1-naphthyl) ethylenediamine dihydrochloride) was added to the mixture. The absorbance of the chromophore formed during the diazotization of nitrite with sulphanilamide and subsequent coupling with naphthyl ethylenediamine was measured at $546 \mathrm{~nm}$. Standard solutions of ascorbic acid treated in the same way as tests with Greiss reagent served as positive control. The percentage of inhibition was calculated by using the following formula:

$\%$ Inhibition $=\left(A_{0}-A_{t} / A_{0}\right) \times 100$.

Where, $A_{0}$ was the absorbance of the control (without extract) and $A_{t}$ was the absorbance in the presence of the ex- tract. All the tests were performed in triplicate and graph was plotted with the mean $\pm \mathrm{SD}$ values.

\section{In Vivo Hepatoprotective Activity}

\section{Test Animals}

Wistar rats (170-250 g) of either sex were used for the study. The animals were housed in large, clean polypropylene cages in a temperature-controlled room $\left(22 \pm 2{ }^{\circ} \mathrm{C}\right)$ with relative humidity (45-55\%) under 12-h light-dark cycles. All the animals were acclimatized to the surrounding laboratory environment for one week prior to experiments. All the animals were provided with a standard rodent pellet diet and drinking water ad libitum. The care and use of laboratory animals were strictly in accordance with the guidelines prescribed by Committee for the Purpose of Control and Supervision of Experiments on Animals (CPCSEA), India.

\section{Experimental Design}

All the rats were divided into 6 groups of 6 rats each. Group I served as normal control and received only the vehicle $(1 \mathrm{~mL} / \mathrm{kg} /$ day of $1 \%$ Tween $80 ;$ p.o.). Group II received $\mathrm{CCl}_{4} 1 \mathrm{~mL} / \mathrm{kg}$ (1:1 of CCl4 in olive oil) i.p. once daily for 7 days. Group III received $\mathrm{CCl}_{4} 1 \mathrm{~mL} / \mathrm{kg}\left(1: 1\right.$ of $\mathrm{CCl}_{4}$ in olive oil) i.p. and silymarin $100 \mathrm{mg} / \mathrm{kg}$ orally (p.o.) for 7 days. And groups IV, V and VI were administered MEUD at 100, 200 , and $400 \mathrm{mg} / \mathrm{kg}$ body weight p.o., respectively and dose of $1 \mathrm{~mL} / \mathrm{kg}$ i.p. of $\mathrm{CCl}_{4}\left(1: 1\right.$ of $\mathrm{CCl}_{4}$ in olive oil) for 7 days.

All the rats were sacrificed by cervical dislocation after $24 \mathrm{~h}$ of the last treatment. Just before sacrifice, under mild ether anesthesia, blood was collected from the rats by retroorbital bleeding method. Serum was separated from the collected blood by centrifuging the clotted blood at $3500 \mathrm{rpm}$ for $15 \mathrm{~min}$ for carrying out further biochemical investigations. Liver was also dissected out for further biochemical studies.

\section{Measurement of Serum Biochemical Parameters}

Serum biochemical parameters including serum aspartate transaminase (AST), alanine transaminase (ALT), alkaline phosphatase (ALP) and total bilirubin levels were estimated by using the Hitachi 912 clinical chemistry automatic analyzer (Roche Diagnostic GmbH, Mannheim, Germany).

\section{Appraisal of Lipid Peroxidation and Superoxide Dismutase (SOD)}

Dissected out liver was cleaned off blood cells by perfusing in chilled normal saline. Then small pieces of the liver were made, placed in $0.1 \mathrm{M}$ phosphate buffer $(\mathrm{pH} \mathrm{7.4)}$, and homogenized using remi homogenizer to obtain $20 \%$ homogenate. The homogenate thus obtained was centrifuged at $3,000 \mathrm{rpm}$ for $15 \mathrm{~min}$ and the supernatant was collected in an Eppendorf tube. This supernatant was further centrifuged at $12,000 \mathrm{rpm}$ for $30 \mathrm{~min}$. The final supernatant was used for the estimation of MDA as a lipid peroxidation marker [23]. Superoxide dismutase (SOD) was also measured by the method described previously [24].

\section{Anthelmintic Activity}

\section{Experimental Worms}

Indian adult earth-worms (Pheretima posthuma) were collected from moist soil and washed with normal saline to 
remove all faecal matter. The earth-worms of $4-5 \mathrm{~cm}$ in length and $0.1-0-2 \mathrm{~cm}$ in width were selected for the study of anthelmintic activity. Indian adult earth-worms have been used for the initial evaluation of anthelmintic compounds in vitro due to its easy availability, anatomical and physiological resemblance with intestinal round worm parasite of human beings. [25].

\section{Screening of Anthelminthic Activity}

Anthelminthic activity was evaluated according to the method described previously [26]. MEUD was dissolved in a minimum volume of $1 \% \mathrm{w} / \mathrm{v}$ of Tween 80 solution and the volume was adjusted to $10 \mathrm{~mL}$ with saline water to make desired concentrations. Five groups of Indian earth-worms consisting of six earth-worms in each group were released into the $50 \mathrm{~mL}$ of formulations of different concentration prepared. These concentrations i.e. 25,50 , and $100 \mathrm{mg} / \mathrm{mL}$ of extract were prepared and used for the study. Observations were made for the time taken to paralyse or death of individual worm. Paralysis was said to occur when the worms did not revive even in normal saline. Death was confirmed when the worms lost their motility followed by slight discolouration of their normal body colour.

\section{Statistical Analysis}

The amount of extract needed to inhibit free radicals concentration by $50 \%\left(\mathrm{IC}_{50}\right)$ was graphically estimated using a linear regression analysis. Data for hepatoprotective activity and anthelmintic study were expressed as mean \pm SD for 6 animals or worms. All other data were expressed as mean of three independent analyses.

\section{RESULTS AND DISCUSSION}

\section{Preliminary Phytochemical Screening}

MEUD were subjected to preliminary phytochemical screening using different chemical methods and the results showed the presence of phytosterols, saponins, flavanoids, tannins, hydrolysable tannins, phenolic compounds, and proteins and amino acids. The test for alkaloid showed negative result.

\section{Determination of Total Phenolic Content}

Due to their hydroxyl groups, phenols and phenolics are very important phytoconstituent with free radical scavenging ability. But the antioxidant effects do not necessarily always correlate with the presence of large quantities of phenolics and related compounds [17]. MEUD was also subjected to assay for total phenolic content. The amount of total phenolics in this present study was found to be $6.35 \mathrm{mg} \mathrm{GAE} / \mathrm{g}$ extract.

\section{In Vitro Antioxidant Activity}

\section{Total Antioxidant Activity Determination in Linoleic Acid System}

The total antioxidant activity of MEUD was done by thiocyanate method. The extract showed effective and powerful antioxidant activity at a concentration of $250 \mu \mathrm{g} / \mathrm{mL}$. The antioxidant activity of MEUD initially was increased with an increasing time of incubation and then it showed a decrease in activity further with increasing time of incubation. The influence of $250 \mu \mathrm{g} / \mathrm{mL}$ concentration of the extract on peroxidation of linoleic acid emulsion is shown in Fig. (1). The extract at $250 \mu \mathrm{g} / \mathrm{mL}$ concentration demonstrated higher antioxidant activity than $250 \mu \mathrm{g} / \mathrm{mL}$ concentration of $\alpha$-Tocopherol. The percentage inhibition of peroxidation of the extract in linoleic acid system was found to be $62.34 \%$. And percentage inhibition of $250 \mu \mathrm{g} / \mathrm{mL}$ concentration of $\alpha$-Tocopherol was found as $34.41 \%$.

\section{Effect on Reducing Power Assay}

The reducing power of MEUD compared to $\alpha$ Tocopherol is shown in Fig. (2). In the reducing power measurement, $\mathrm{Fe}^{3+}-\mathrm{Fe}^{2+}$ transformation in the presence of extract samples was investigated using the method of Oyaizu [19]. The reducing power of the extract was found to be increased with increasing concentration of the extract. The extract revealed higher reducing power than $\alpha$-Tocopherol at all the concentrations under investigation.

\section{Effect on DPPH Radical Scavenging Activity}

Over production of free radicals beyond the body's ability to protect itself by antioxidant defense systems cause oxidative stress and forms the biological basis of chronic condition [27]. Results from this study revealed MEUD as a powerful free radical scavenger, which can block the free radical induced damage in the physiological system. Measuring scavenging capability of stable DPPH radical for evaluation of antioxidant activity in vitro is a widely used quick method compared to other methods. As DPPH is a stable free radical and it accepts an electron or hydrogen radical to become a stable diamagnetic molecule. Decrease in absorbance at $517 \mathrm{~nm}$ by scavenging of DPPH radicals by antioxidants was observed. Hence, DPPH is unremarkably used as a substrate to evaluate antioxidant activity of different antioxidants. In this present experimental setup, BHA was used as a standard radical scavenger. Fig. (3) shows the decrease in concentration of DPPH radical due to scavenging capability of the extract and standard compound (BHA) at different studied concentrations $(50-250 \mu \mathrm{g} / \mathrm{mL})$. The scavenging ability of MEUD on DPPH radical was found to be less than BHA. The percent DPPH scavenging effect of the extract and the standard (BHA) were found to be 57.34 and $69.05 \%$, respectively at the concentration of $100 \mu \mathrm{g} / \mathrm{mL}$. The results indicated the plant as a strong scavenger of DPPH radical comparable to standard BHA. At $250 \mu \mathrm{g} / \mathrm{mL}$ concentration the extract showed slightly stronger DPPH scavenging effect than BHA. The percent DPPH scavenging effect of the extract and the standard were found to be 98.35 and $97.90 \%$, respectively at the concentration of $250 \mu \mathrm{g} / \mathrm{mL}$. The $\mathrm{IC}_{50}$ values of the extract and BHA were calculated using the linear regression equation. The calculated $\mathrm{IC}_{50}$ values of MEUD and the standard compound (BHA) were found to be $105.16 \mu \mathrm{g} / \mathrm{mL}$ and $87.32 \mu \mathrm{g} / \mathrm{mL}$, respectively.

\section{Effect on Nitric Oxide Scavenging Activity}

Nitric oxide or reactive nitrogen species (RNS) are very reactive and cause severe pathological changes in the cellular structure and functional behavior of cellular components [28]. In this experimental design, nitric oxide scavenging by MEUD was evaluated by observing the reduction of linear time-dependent nitrite production in the sodium nitroprus- 


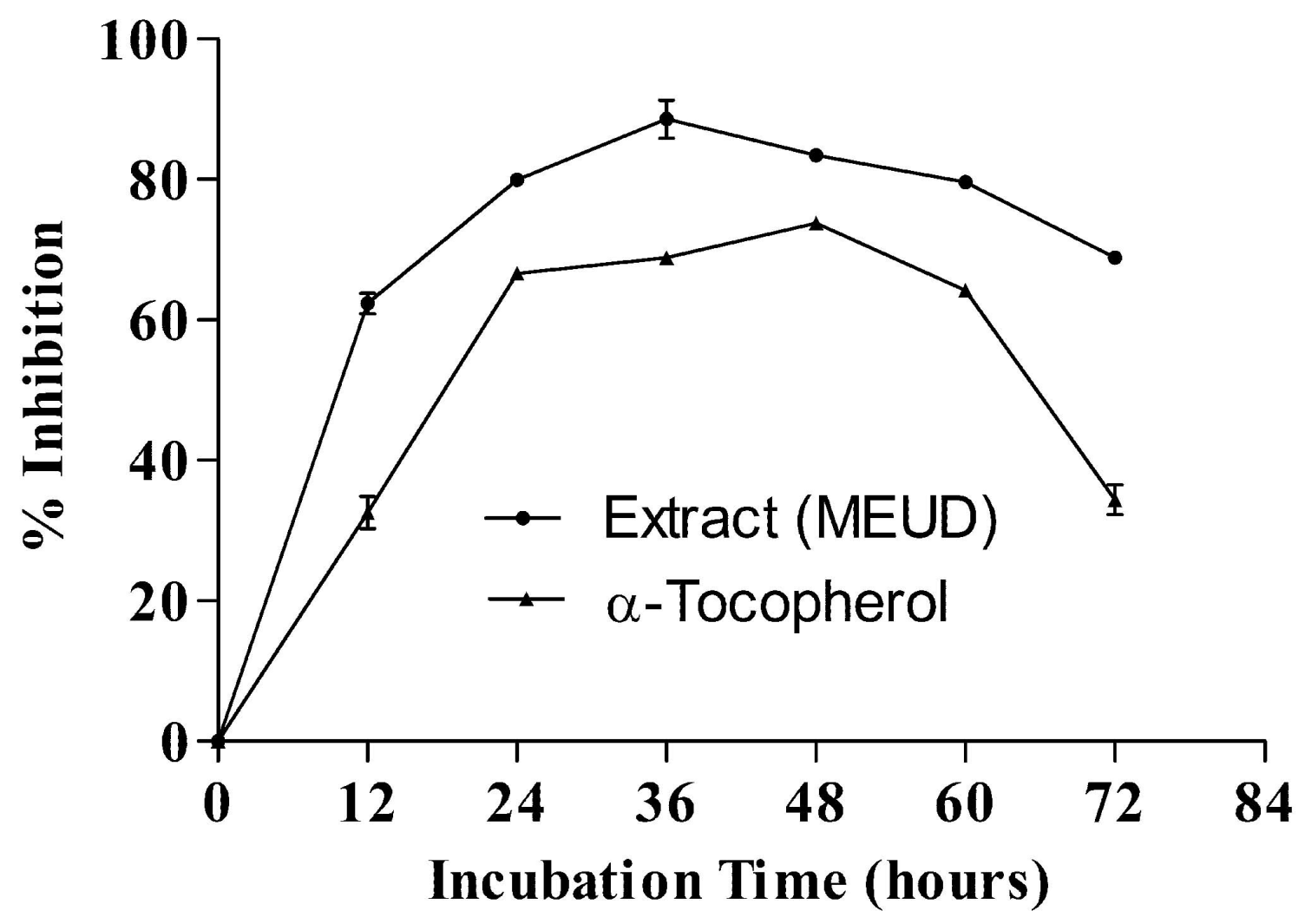

Fig. (1). Total antioxidant activity of MEUD and $\alpha$-Tocopherol at $250 \mu \mathrm{g} / \mathrm{mL}$ concentration. Results are mean \pm SD of three parallel measurements.

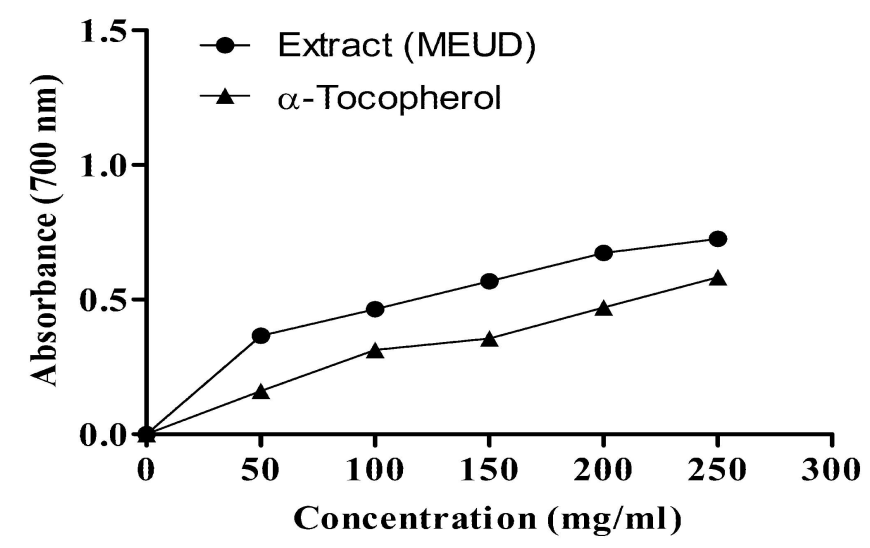

Fig. (2). Reducing power of MEUD and $\alpha$-Tocopherol by spectrophotometric detection of $\mathrm{Fe}^{3+-} \mathrm{Fe}^{2+}$ transformation. Results are mean $\pm \mathrm{SD}$ of three parallel measurements.

side-PBS system. Fig. (4) shows the concentration dependent scavenging of nitric oxide by MEUD and standard compound (Ascorbic acid). All the concentrations of the plant extract $(50-250 \mu \mathrm{g} / \mathrm{mL})$ were found to possess the nitric oxide scavenging activity. The nitric oxide scavenging activity of MEUD was found to be lower than ascorbic acid. The percentage inhibition of nitric oxide by MEUD and standard compound was calculated and found as 63.76 and $82.02 \%$ at the concentration of $250 \mu \mathrm{g} / \mathrm{mL}$, respectively. Based upon the linear regression analysis of the data the $\mathrm{IC}_{50}$ values were found as $176.39 \mu \mathrm{g} / \mathrm{mL}$ and $121.11 \mu \mathrm{g} / \mathrm{mL}$ for MEUD and ascorbic acid, respectively.

\section{In Vivo Hepatoprotective Activity}

\section{Effect of MEUD on the Measurement of Serum Biochemi- cal Parameters}

The hepatoprotective effects of MEUD on serum biochemical parameters in $\mathrm{CCl}_{4}$-treated rats are shown in Table 1. A significant increase in serum AST, ALT, ALP and total bilirubin levels were observed in rats treated with $\mathrm{CCl}_{4}$ (Group II) compared to vehicle treated control group animals (Group I). Pretreatment with MEUD (100, 200, and 400 $\mathrm{mg} / \mathrm{kg}$ ) for 7 days (Groups IV, V and VI) demonstrated significant hepatoprotection as evident by AST, ALT, ALP and total bilirubin levels compared to the toxic control group 


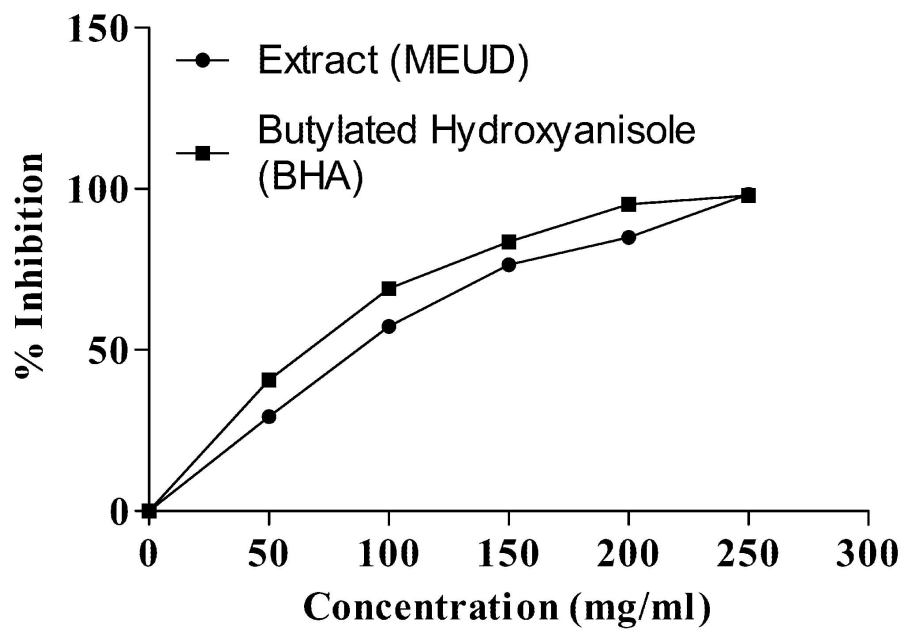

Fig. (3). Free radical scavenging activity of different concentrations of MEUD and BHA by DPPH radicals. Results are mean \pm SD of three parallel measurements.

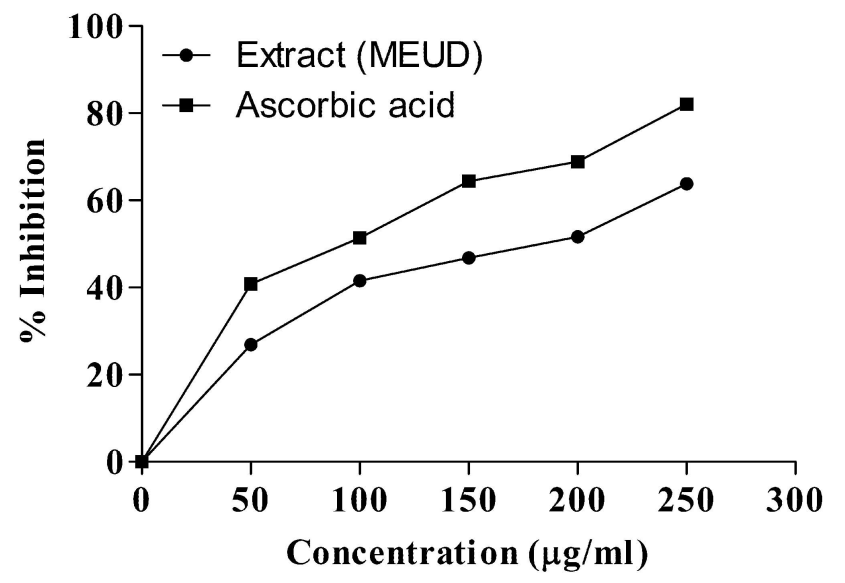

Fig. (4). Percentage inhibition of nitric oxide radical by MEUD and Ascorbic acid. Results are mean \pm SD of three parallel measurements.

(Group II). Pretreatment with the standard hepatoprotective agent, Silymarin (Groups III) also reduced all measured serum biochemical markers towards normal levels. The liver mainly detoxifies toxic chemicals and drugs and is the main target organ for all potential toxic agents. Carbon tetrachloride $\left(\mathrm{CCl}_{4}\right)$ is the most extensively used hepatotoxic agent to investigate hepatoprotective activity on various experimental animal models. The $\mathrm{CCl}_{4}$ induced experimental hepatic damage also bear a resemblances with viral hepatitis histologically [29]. Biotransformation of $\mathrm{CCl}_{4}$ in liver occurs by cytochrome $\mathrm{P}_{450}$ enzymes to produce very reactive $\mathrm{CCl}_{3}$ radical. This active $\mathrm{CCl}_{3}$ radical produces trichloromethylperoxyl radical $\left(\mathrm{CCl}_{3} \mathrm{O}_{2}\right)$ after reacting with oxygen, which is then covalently binds with cellular macromolecules and biomembranes to cause lipid peroxidation of the lipid membranes of the hepatic tissue. Peroxide products finally spark the leakage of biomarkers produced like MDA. This whole cascade of biochemical events ultimately causes hepatic damage by disturbing of cellular integrity [30]. Normally liver contains AST, ALT and ALP as hepatobillary enzymes in high concentrations. Due to hepatic damage and necrosis serum hepatobillary enzymes (AST, ALT and ALP) will be leaked into the circulation which raises serum concentration of these enzymes [31, 32]. In the present study cellular breakage and loss of functional integrity of cell membranes in liver tissues elevated the serum AST, ALT and ALP levels in $\mathrm{CCl}_{4}$ treated animals confirming hepatotoxicity. Increased level of bilirubin (a breakdown product of heme in red blood cells) further, confirmed hepatotoxicity as bilirubin had been proved as a clinical and pathophysiological indicator of necrosis of liver tissues. Group IV, V and VI animals when pretreated with MEUD produced a significant decrease in serum AST, ALT, ALP and total bilirubin levels as compared to $\mathrm{CCl}_{4}$ treated group (Group II). The results reflected a considerable prophylactic inhibition of the degree of hepatic necrosis and concomitantly leakage of intracellular enzymes by stabilizing hepatic cellular membranes.

\section{Effect of MEUD on MDA and SOD levels}

A significant increase in MDA level was observed in the toxic control group (Group I) of animals when compared with the normal control group (Group II). Elevated MDA level indicated Lipid peroxidation which is a hallmark sign of hepatic damage and necrosis. Pretreatment with MEUD at 100,200 , and $400 \mathrm{mg} / \mathrm{kg}$ of doses significantly decreased the MDA levels, which were almost similar to those of rats receiving the standard drug Silymarin. As a marker of antioxidant defense system SOD level was also found to be elevated significantly in MEUD treated groups. The extract at the highest studied dose $(400 \mathrm{mg} / \mathrm{kg})$ demonstrated maximum hepatoprotection as shown in Table 1. As lipid peroxidation is considered as a hallmark mechanism of hepatotoxicity along with oxidative stress and other free radical damage occurred in the biochemical cascade, evaluation of antioxi- 
Table 1. Effects of MEUD on Serum Biochemical Parameters in $\mathrm{CCl}_{4}$-Intoxicated Rats

\begin{tabular}{|c|c|c|c|c|c|c|c|}
\hline Group & Treatment & $\begin{array}{l}\text { AST (SGOT) } \\
(\text { IU/L) }\end{array}$ & $\begin{array}{l}\text { ALT (SGPT) } \\
(\text { IU/L) }\end{array}$ & $\begin{array}{l}\text { ALP } \\
(I U / L)\end{array}$ & $\begin{array}{l}\text { Serum } \\
\text { BILLIRUBIN } \\
(\mathrm{mg} / \mathrm{dL})\end{array}$ & $\begin{array}{l}\text { MDA } \\
\text { (U/mg } \\
\text { Protein) }\end{array}$ & $\begin{array}{l}\text { SOD } \\
\text { (U/mg } \\
\text { Protein) }\end{array}$ \\
\hline II & $\mathrm{CCl}_{4} 1 \mathrm{~mL} / \mathrm{kg}$ (i.p.) & $\begin{array}{ll}259.96 & \pm \\
2.51^{* * *} & \end{array}$ & $222.46 \pm 2.94$ & $\begin{array}{l}303.29 \\
4.46^{* * *}\end{array}$ & $3.98 \pm 0.14^{* * *}$ & $\begin{array}{l}11.43 \\
0.28^{* * *}\end{array} \quad \pm$ & $2.46 \pm 0.27^{* * *}$ \\
\hline IV & $\begin{array}{l}\text { MEUD } 100 \mathrm{mg} / \mathrm{kg} \\
+\mathrm{CCl}_{4} \text { (prophylactic) }\end{array}$ & $\underset{* * *}{150.21 \pm 2.69}$ & $130.14 \pm 1.33$ & $\begin{array}{l}188.24 \\
3.21^{* * *}\end{array} \quad \pm$ & $2.25 \pm 0.07^{* * *}$ & $6.06 \pm 0.04^{* * *}$ & $3.80 \pm 0.13^{* * *}$ \\
\hline V & $\begin{array}{l}\text { MEUD } 200 \mathrm{mg} / \mathrm{kg} \\
+\mathrm{CCl}_{4} \text { (prophylactic) }\end{array}$ & \begin{tabular}{ll|}
116.31 & \pm \\
$3.51^{* * * *}$ &
\end{tabular} & $94.13 \pm 0.79$ & $\begin{array}{l}132.26 \\
6.29^{* * *}\end{array}$ & $1.85 \pm 0.04^{* * *}$ & $5.27 \pm 0.07^{* * *}$ & $4.18 \pm 0.20^{* * *}$ \\
\hline
\end{tabular}

MEUD: Methanol extract of Urtica dioica leaves. Data are expressed as mean $\pm \mathrm{SD}(\mathrm{n}=6)$..

One-way ANOVA Turkey post hoc: $* * * p<0.001$.

Table 2. Anthelmintic Activity of MEUD

\begin{tabular}{|l|l|c|c|c|}
\hline S. No. & Groups & Concentration $(\mathrm{mg} / \mathrm{mL})$ & \multicolumn{2}{|c|}{ Pheretima Posthuma } \\
\cline { 3 - 5 } & & & $\begin{array}{c}\text { Time taken for paralysis (P) in min. } \\
\text { (Mean } \pm \text { SD) }\end{array}$ & $\begin{array}{c}\text { Time Taken for Death (D) in min. } \\
\text { (Mean } \pm \text { SD) }\end{array}$ \\
\hline \hline 1 & Control & $1 \% \mathrm{w} / \mathrm{v}$ Tween 80 & No paralysis occurs & No death occurs \\
\hline 2 & Piperazine citrate & 15 & $15.000 \pm 2.000$ & $15.500 \pm 1.761$ \\
\hline 3 & Albendazole & 20 & $13.333 \pm 0.8165$ & $13.833 \pm 0.7528$ \\
\hline 4 & MEUD & 25 & $42.000 \pm 2.191$ & $47.000 \pm 0.8944$ \\
\hline 5 & MEUD & 50 & $35.333 \pm 1.751$ & $39.500 \pm 1.049$ \\
\hline 6 & MEUD & 100 & $28.833 \pm 1.169$ & $35.000 \pm 1.265$ \\
\hline
\end{tabular}

Data were expressed as mean \pm SD for 6 worms $(n=6)$.

dant efficacy and lipid peroxidation inhibition activity are regarded as extremely important parameter indicative of the possible mechanism of hepatoprotection. In the present study, increased MDA levels in liver indicated increased lipid peroxidation induced by $\mathrm{CCl}_{4}$ (Group II animals) along with reduced level of SOD in $\mathrm{CCl}_{4}$ treated animals further indicating failure of antioxidant defense mechanism to block peroxidation damage. Pretreatment with MEUD significantly decreased the MDA level towards normalization as evident in Table 1. An increase in the SOD level also suggested the repairment of antioxidant defense system in the MEUD treated animals, which plays an important role in hepatoprotection. Results of this present study clearly revealed that MEUD has proven to be a significant hepatoprotective along with its considerable antioxidant mechanisms.

\section{Anthelmintic Activity}

Results for anthelmintic activity indicated the predominant effect of albendazole and piperazine citrate as strong anthelminthic that caused a flaccid paralysis of the worms. Inhibition of micro tubule polymerization by albendazole and thereby induction of immobilization produced paralysis and death of worms [33]. Significant dose dependent anthelminthic activity was evident by MEUD at 25, 50, and $100 \mathrm{mg} / \mathrm{mL}$ concentrations as presented in Table $\mathbf{2}$ and Fig. (5). Results clearly indicated that $100 \mathrm{mg} / \mathrm{mL}$ concentration of MEUD has the highest potency as an anthelmintic (took least time to cause paralysis and death of worms) when compared to standard drug piperazine citrate and albendazole.

\section{CONCLUSIONS}

The present study demonstrates the hepatoprotective, prophylactic, and antioxidant effects of MEUD against $\mathrm{CCl}_{4}$-induced hepatic injury in Wister rats. Anthelmintic activity was also assessed by using Indian earth worms. Based upon the results from different in vitro antioxidants models as well as in vivo hepatoprotective screening it is evident that MEUD has an effective and considerable 


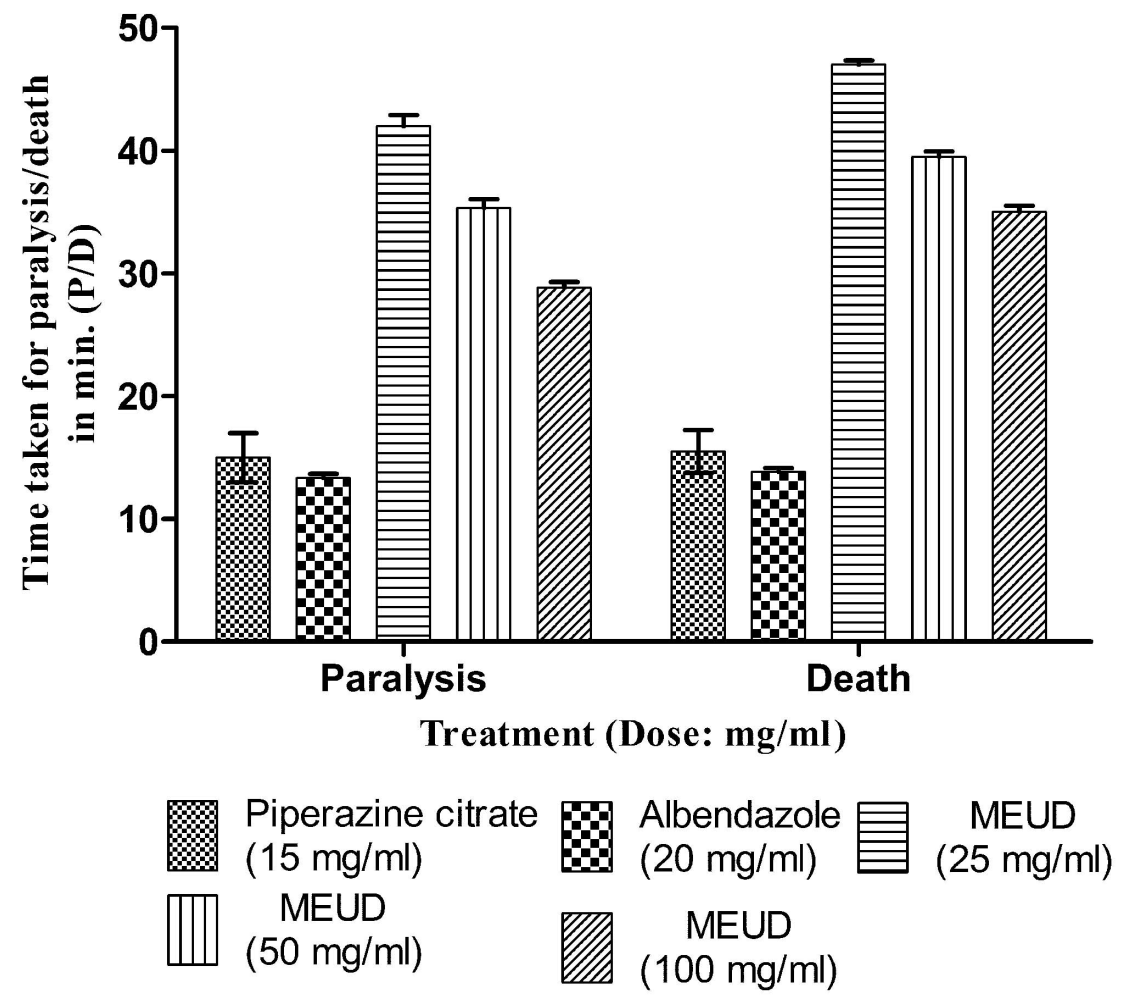

Fig. (5). Anthelmintic activity of MEUD. (Time taken for paralysis and death).

hepatoprotective profile with the antioxidant mechanisms. The preliminary phytochemical investigation and previous phytochemical reports also suggested several phytoconstituents that may be responsible for the observed activity. The present study also clearly indicated the traditional ethno medical claim of the plant as anthelminthic and also its use in hepatopathy. We have already undertaken a further investigation on the isolation and identification of compounds related to the antioxidant, hepatoprotective and anthelminthic activity in this plant, which may lead to new chemical leads with potential for clinical use and further investigation.

\section{ACKNOWLEDGEMENTS}

We are thankful to Dr. S. K. Sharma, Botanist, Research Institute in Indian System of Medicine, Joginder Nagar, Mandi, Himachal Pradesh for identifying the plant. We are also grateful to Prof. D. N. Sharma for his valuable advice and noble support throughout the progress of this entire work.

\section{CONFLICT OF INTEREST}

None declared

\section{ABBREVIATIONS}

$\begin{array}{ll}\text { ALP } & =\text { Alkaline Phosphatase } \\ \text { ALT } & =\text { Alanine Transaminase } \\ \text { AST } & =\text { Aspartate Transaminase } \\ \text { BHA } & =\text { Butylated hydroxyanisole } \\ \text { CPCSEA } & =\begin{array}{l}\text { Committee for the Purpose of Control and } \\ \end{array} \quad \text { Supervision of Experiments of Animals }\end{array}$

$\begin{array}{ll}\text { DMSO } & =\text { Dimethylsulphoxide } \\ \text { DPPH } & =1-1 \text {-Diphenyl-2-Picryl hydrazyl } \\ \text { GAE } & =\text { Gallic Acid Equivalent } \\ \text { IC }_{50} & =\text { Inhibitory Concentration 50\% } \\ \text { MDA } & =\text { Malonaldehyde } \\ \text { MEUD } & =\text { Methanol Extract of Urtica dioica } \\ \text { PBS } & =\text { Phosphate Buffered Saline } \\ \text { RNS } & =\text { Reactive Nitrogen Species } \\ \text { ROS } & =\text { Reactive Oxygen Species } \\ \text { SD } & =\text { Standard Deviation } \\ \text { SOD } & =\text { Superoxide Dismutase } \\ \text { TCA } & =\text { Trichloroacetic acid }\end{array}$

\section{REFERENCES}

[1] Khare, C.P. Indian Medicinal Plants: An Illustrated Dictionary. Springer Science+BusinessMedia, LLC.: New York, 2007.

[2] Chopra, R.N.; Nayar, S.L.; Chopra, I.C. Supplement to Glossary of Indian Medicinal Plants. Council of Scientific \& Industrial Research: New Delhi, 1956.

[3] Beintema, J.J.; Peumans, W.J. The primary structure of stinging nettle (Urtica dioica) agglutinin A two-domain member of the hevein family. FEBS Lett., 1992, 299(2), 131-134.

[4] Farzami, B.; Ahmadvand, D.; Vardasbi, S.; Majin, F.J.; Khaghani, S. Induction of insulin secretion by a component of Urtica dioica leave extract in perifused Islets of Langerhans and its in vivo effects in normal and streptozotocin diabetic rats. $J$. Ethnopharmacol., 2003, 89(1), 47-53.

[5] Guil-Guerrero, J.L.; Rebolloso-Fuentes, M.M.; Isasa, M.E.T. Fatty acids and carotenoids from stinging nettle (Urtica dioica L.). $J$. Food Comp. Anal., 2003, 16(2), 111-119. 
[6] Bnouham, M.; Merhfour, F.-Z.; Ziyyat, A.; Mekhfi, H.; Aziz, M.; Legssyer, A. Antihyperglycemic activity of the aqueous extract of Urtica dioica. Fitoterapia, 2003, 74(7-8), 677-681.

[7] Kraus, R.; Spiteller, G. Phenolic compounds from roots of Urtica dioica. Phytochemistry, 1990, 29(5), 1653-1659.

[8] Kraus, R.; Spiteller, G. Terpene diols and terpene diol glucosides from roots of Urtica dioica. Phytochemistry, 1991, 30(4), 12031206.

[9] Peumans, W.J.; De Ley, M.; Broekaert, W.F. An unusual lectin from stinging nettle (Urtica dioica) rhizomes. FEBS Lett., 1984, $177(1), 99-103$

[10] Tahri, A.; Yamani, S.; Legssyer, A.; Aziz, M.; Mekhfi, H.; Bnouham, M.; Ziyyat, A. Acute diuretic, natriuretic and hypotensive effects of a continuous perfusion of aqueous extract of Urtica dioica in the rat. J. Ethnopharmacol., 2000, 73 (1-2), 95100.

[11] Halliwell, B.; Gutleridge, M. Review article. Oxygen toxicity, oxygen radicals, transition metals and disease. Biochem. J., 1984, $219,1-4$.

[12] Li, X.M.; Li, X.L.; Zhou, A.G. Evaluation of antioxidant activity of the polysaccharides extracted from Lycium barbarum fruits in vitro. Eur. Polymer J., 2007, 43, 488-497.

[13] Kataki, M.S.; Ahmed, M.Z.; Awasthi, D.; Tomar, B.; Mehra, P.; Yadav, R.S.; Rajak, P. In vitro antioxidant profile of Wedelia calandulaceae L. leaves. Pharmacologia, 2012, 3(3), 75-83.

[14] Gülçin, I.; Oktay, M.; Küfrevioglu, Ö.I.; Aslan, A. Determination of antioxidant activity of lichen Cetraria islandica (L) Ach. $J$. Ethnopharmacol., 2002, 79(3), 325-329.

[15] Ellnain-Wojtaszek, M.; Kruczynski, Z.; Kasprzak, J. Investigation of the free radical scavenging activity of Ginkgo biloba L. leaves. Fitoterapia, 2003, 74(1-2), 1-6.

[16] Harborne, J.B. Phytochemical methods: A guide to Modern Techniques of Analysis. Chapman and Hall Publishers: London, 1973.

[17] Slinkard, K.; Singleton, V.L. Total Phenol analysis: Automation and comparison with manual methods. Amer. J. Enol.Viticul., 1977, $28,49-55$

[18] Mitsuda, H.; Yuasumoto, K.; Iwami, K. Antioxidation action of indole compounds during the autoxidation of linoleic acid. Eiyo to Shokuryo, 1996, 19, 210-214.

[19] Oyaizu, M. Studies on product of browning reaction prepared from glucose amine. Jpn. J. Nutr., 1986, 44, 307-315.
[20] Shimada, K.; Fujikawa, K.; Yahara, K.; Nakamura, T. Antioxidative properties of xanthin on autoxidation of soybean oil in cyclodextrin emulsion. J. Agric. Food Chem., 1992, 40, 945-948.

[21] Kumaran, A.; Joel Karunakaran, R. Antioxidant activities of the methanol extract of Cardiospermum halicacabum. Pharm. Biol., 2006, 44 (2), 146-151.

[22] Sreejayan, N.; Rao, M.N.A. Nitric oxide scavenging by curcuminoids. J. Pharm. Pharmacol., 1997, 49, 105-107.

[23] Nourooz-Zadeh, J.; Tajaddini-Sarmadi, J.; McCarthy, S.; Betteridge, D.J.; Wolff, S.P. Elevated levels of authentic plasma hydroperoxides in NIDDM. Diabetes, 1995, 44, 1054-1058.

[24] Misra, H.P.; Fridovich, I. Role of superoxide anion in the autoxidation of epinephrine and a simple assay for superoxide dismutase. J. Biol. Chem., 1972, 247, 3170.

[25] Szewezuk, V.D.; Mongelli, E.R.; Pomilio, A.B. Antiparasitic activity of Meliaazadirach growing in Argentina. Mol. Med. Chem., 2003, 1, 54-57.

[26] Nirmal, S.A.; Malwodkar, G.; Laware, R.B. Anthelmintic activity of Pongamiaglabra. Songklanakarin J. Sci. Technol., 2007, 29(3), $755-757$.

[27] Jainu, M.; Devi, C.S.S. In vitro and in vivo evaluation of freeradical scavenging potential of Cissus quadrangularis. Pharm. Biol., 2005, 43(9), 773-779.

[28] Ashokkumar, D.; Thamilselvan, V.; GP, S.; Mazumder, U.K.; Gupta, M. Antioxidant and Free Radical Scavenging Effects of Lippia nodiflora. Pharm. Biol., 2008, 46(10-11), 762-771.

[29] James, G.W.L.; Pickering, R.W. The protective effect of a novel compound RU-18492 on galactosamine induced hepaptotoxicity in rats. Drug Res., 1976, 26, 2197-2199.

[30] Thabrew, M.I.; Joice, P.D.T.M.; Rajatissa, W.A. Comparative study of the efficacy of Paetta indica and Osbeckia octandra in the treatment of liver dysfunction. Planta Med., 1987, 53, 239-241.

[31] Wolf, P.L. Biochemical diagnosis of liver diseases. Indian J. Clin. Biochem., 1999, 14, 59-90.

[32] Drotman, R.; Lawhan, G. Serum enzymes are indications of chemical induced liver damage. Drug Chem. Toxicol., 1978, 1, 163-171.

[33] Brunton, L.L.; Lazo, J.S.; Parker, K.L. Goodman \& Gilman's The Pharmacological Basis of Therapeutics. 9 ed.; McGraw- Hill: New York, 1996.

Received: November 25, 2011

Revised: December 25, 2011

Accepted: December 29, 2011

(C) Kataki et al.; Licensee Bentham Open.

This is an open access article licensed under the terms of the Creative Commons Attribution Non-Commercial License (http:/creativecommons.org/ licenses/ by-nc/3.0/) which permits unrestricted, non-commercial use, distribution and reproduction in any medium, provided the work is properly cited. 